\title{
Recent Challenges in Electrical Engineering and the Solution with IT
}

\author{
B Koti Reddy, B SreeBindu
}

\begin{abstract}
Electrical engineering is a broad field right from Electrical Power Generation to Distribution to end users. With deep penetration of Power Electronic Devices (PED) into electrical system, it has become complex to understand and control, but has given many advantages. Computer engineering is also an integrated branch of several fields of engineering like electrical and computers, which focuses on programming, and integration with hardware devices. Electrical engineering is always a challenging field which requires a regular up keeping with proper control and communication system. This paper aims to review the existing electrical power system, various challenges like increased demand, cyber attacks, power electronic technology trends, the opportunities emerged and the action plan to mitigate them with the use of Information Technology(IT) for a sustainable development.
\end{abstract}

Index Terms-Communication, Electrical, Electronics, GOT, IOT, Smart Grid.

\section{INTRODUCTION}

Electrical engineering is a broad field which comprises of Power Generation, Transmission, Distribution, Protection, Switchgear, Utilization through various Conversions, and Measurement. The schematic diagram of all these divisions is shown in Fig. 1. In early days, Electrical engineering is mainly focusing on generation and distribution of power to end users through mechanical modes. With the advancement of power electronic technology, everybody started using electronic devices in almost all the electrical equipment directly or indirectly through their control systems. Invention and regular up gradation of computers has made everything automated in all the division of Electrical engineering. Also the new techniques like FACTS (Flexible Alternating Current Transmission System) [1], and High Voltage Direct Current Transmission System (HVDC) [2]. has made the electrical system more efficient but with some risks which are challenging the integrity of electrical engineering and its constituents.
Revised Version Manuscript Received on 10 September, 2019. B Koti Reddy, Scientific Officer, DAE, Mumbai, Maharashtra, India. (Email: kotireddy1965@gmail.com)

B SreeBindu, ECE, GNITS, Hyderabad, Telangana, India.

(Email: bsreebindureddy@gmail.com).

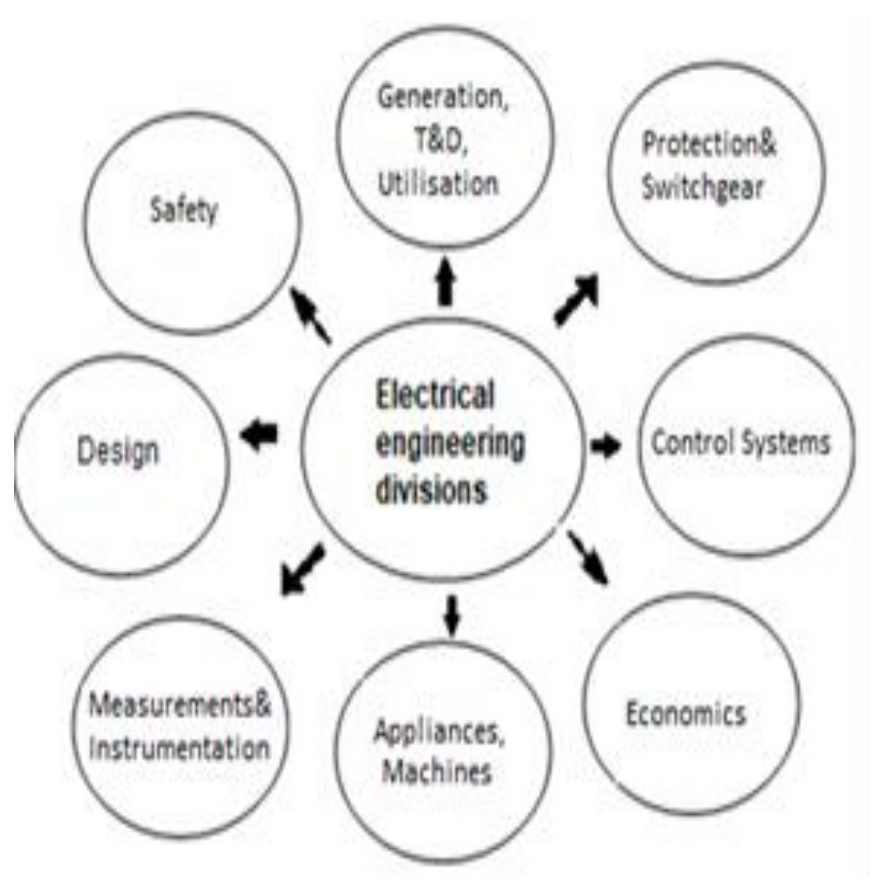

Fig. 1 Divisions of Electrical engineering

However, the availability of proper control techniques and various advanced \& fast communication systems [3] like LAN (Local Area Network), NAN (Neighborhood Area Network), WAN (Wide Area Network) and HAN (Home Area Network) etc. made it easy to eliminate these risks. But these latest communication systems also being attacked by certain malwares [4]. Also IT with computers are playing a vital role in operation and management of electrical power system networks.

\section{II.RECENT CHALLENGES IN POWER SYSTEM}

With the World Energy Council's estimated electrical energy requirement of 40 PWh (Peta Watt hours) by 2040 [5] which is double to that in the year 2008 and rapid industrialization throughout the globe, there is a continuous demand for sufficient capacity of power generation in a safe and reliably way. To cope up with the demand and to ensure safe, secure and reliable power utilization, the electrical power system needs to consider the following challenges that might arise in every segment right from generation to utilization. The major risks will be described in following sections briefly. 


\section{A. GENERATION}

The rate of exhaustion of natural resources like oil and coal raises serious concerns about sustainability and reliability. As an alternative, electricity from renewable sources like solar and wind power technologies ensures sustainable development in addition to conserving natural resources.

Also, the evolution of Distributed Generation (DG) at user level and de-regulated generation models also cause a major change in power generation sector. Integrating these new models to the exiting power grid involves several challenges like stability, synchronization, fault currents and harmonics due to Power Electronic Devices (PED). And to maintain such a complex and hybrid system, there is a need of sophisticated software technology that can monitor and maintain these systems efficiently.

\section{B. Transmission And Distribution}

The tremendous development in the renewable energy and distributed generation has increased the complexity of the transmission and distribution system. Additionally, abrupt changes in load profile due to various types of new loads like Electric Vehicles (EV), mobile phones, portable computer chargers, LED lighting and other nonlinear loads increases the stress on the transmission and distribution system. Also, the de-regulated power transmission and distribution models escalated the complexity of power system. All these problems are leading to a need of advanced technical solutions like Smart Grids (SG) and FACTS etc.

\section{Utilisation}

The excessive usage of electricity by various consumers, existing and also new consumers, and with the availability of various electrical \& electronic gadgets like Televisions(TV), computers, smart phones etc., increased the demand for reliable and uninterrupted power supply in addition to taking care the safety of user groups while using these appliances [6]. Here, the major challenge is forecasting the load and deployment of electrical power without much interruption to the consumer. There is also lot of encouragement by local governments to generate and utilize the electrical energy locally, like Roof top solar power, with an option of exporting surplus energy back to the grid. This system requires continuous monitoring, two-way metering and two-way communication systems. Also, smart devices like smart phones, microwave ovens, refrigerators, electric vehicle charging stations communicating with their remote controllers through internet and mobile apps, thus increasing the chances of cyber-attacks. These problems require a strict monitoring system and mitigation plans.

\section{Switchgear And Protection}

Unlike the traditional generation system, introduction of new generation models that generate electricity locally increases the possibility of faults and increased fault current in the system. For example, an earth fault at any of the solar integrated grid will cause fault current contribution not only from utility grid but also from solar generation side which thus increases the net fault current [7] which may cause mal operation of protective relays and also jeopardizing the design adequacy of protective devices. The cause of such faults might be due to several reasons and with many local power generating sources, it becomes difficult to monitor the system. Such a complex grid demands faster isolation of faulty circuits from the healthy system for better stability. Numerical or digital relays that run on simple software with better communication facilities can protect the system by simply sending commands to trip the circuit breakers. But the use of Information Technology (IT) and modern communication tools create new problems like malwares and cyber-attacks which are to be addressed properly.

\section{III.THREATS AND OPPORTUNITIES}

Electrical power system is a large machine made by human kind and like any other system; electrical engineering also has both threats as well opportunities which are described in next paragraphs.

\section{A. Threats}

Various threats encountered by electrical power system are grid stability, environmental conditions, man-made threats, cyber-attacks, the supply-demand mismatch, wrong synchronism between various generation facilities, regulatory obligations, depleted natural resources, non availability of skilled manpower, huge investments, political changes, technological obsolescence and changes, system resilience and so on. To come out of these problems and to grab the opportunities available, electrical engineering is moving towards smart systems with the help of IT, Power electronics and Computers.

\section{B. Opportunities}

The technological advancements in electrical, electronics, computer and communications engineering supporting the global leaders aim of de-carbonized and green power system. The developments and opportunities took place so far and the ongoing solutions are discussed in subsequent sections. By using PED, which has built-in self supervision facility? the overall availability up to $99 \%$ can be achieved.

\section{B.1 Smart Grids (SG)}

The definition of SG per The European Technology Platform, "It is an electricity network that can indigently integrate the actions of all users connected to it-generators, consumers and those that do both - in order to efficiently deliver sustainable, economic and secure electricity suppliers" [8-11]. It is an electrical grid which consists of conventional\& renewable energy resource, smart appliances, smart meters etc. with two-way communication, whose schematic is shown in Fig. 2. It has re-engineered the electrical utility divisions with the use of power electronic conditioning \& communication devices for smooth conditioning and control. 
International Journal of Recent Technology and Engineering (IJRTE) ISSN: 2277-3878, Volume-8, Issue-2S11, September 2019

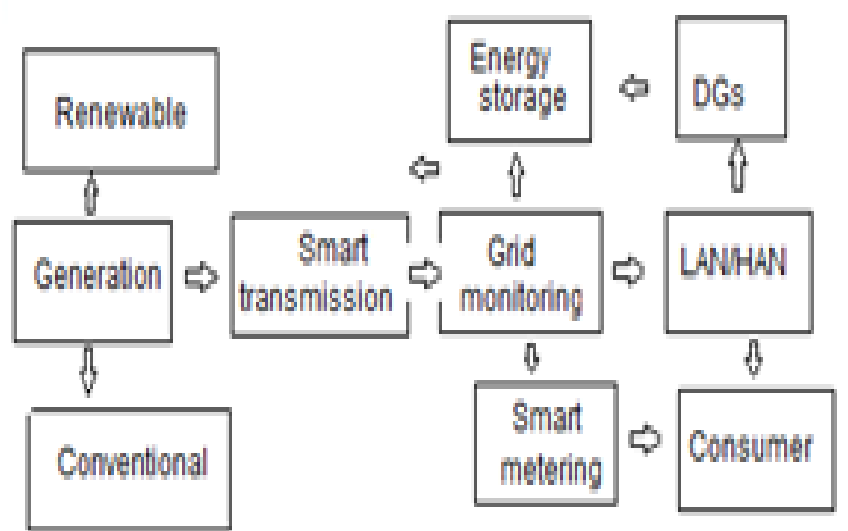

(a) Schematic of SG

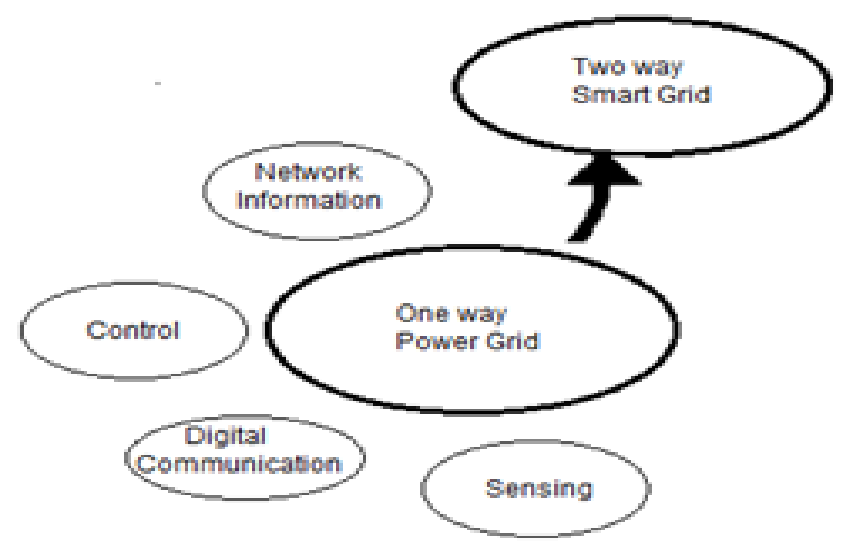

(b) Two way communicating Grid

Fig. 2 SG Model

The overall benefits of SG are shown pictorially in Fig. 3.

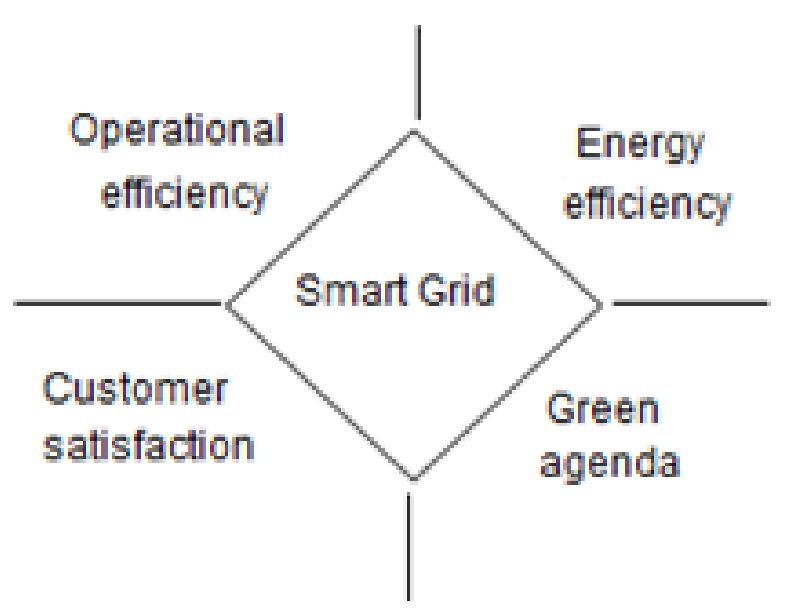

Fig. 3 SG benefits

The smart grid has the capability of self-healing from power disturbances which will improve the reliability of Supplier, operational efficiency \& overall productivity, integration of renewable with reduced carbon emissions, end users choice of managing their energy requirements combined with qualitative power. In nutshell, it is not dumb but smart enough, right from Generator to a switch in a house, to serve the mankind universally. The major advantages of SG in comparison with present Conventional Grid are summarized in table 1.
Table 1 Conventional Vs Smart Grids

\begin{tabular}{|l|l|}
\hline Present Conventional Grid & \multicolumn{1}{|c|}{ Future Smart Grid } \\
\hline Electro-mechanical & Digital \\
\hline One-way communication & Two-way communication \\
\hline Centralized generation & Distributed generation \\
\hline Few or sensor less & Throughout sensors \\
\hline Manualmonitoring & Self-monitoring \\
\hline Manual restoration & Self-healing \\
\hline Failures and blackouts & Adaptive islanding \\
\hline Limited control & Full control \\
\hline Limited customer choices & Many customer choices \\
\hline
\end{tabular}

\section{B.2 MICRO-GRIDS $(M G)$ :}

It is a local mini power grid which can operate as a separate small entity or in collaboration with other small grids. The schematic diagram is shown in Fig. 4, whose scope is generally to have its own local generation and storage facilities with a pre-decided zone restriction.

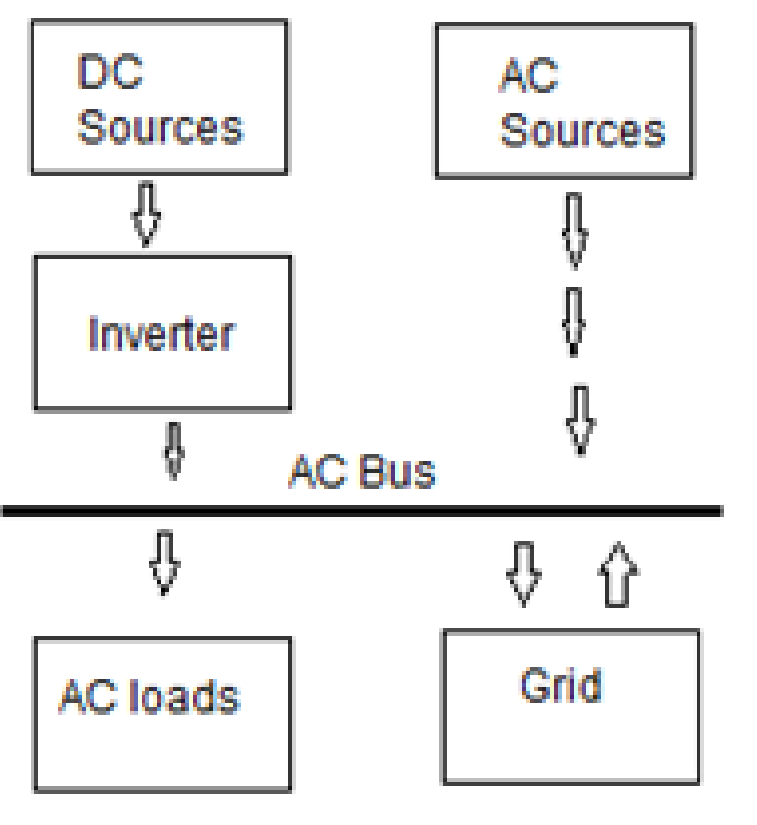

Fig. 4 Micro-Grid concept

The major comparison between SG and MG are shown in Table 2 .

Table 2 Comparison between SG and MG

\begin{tabular}{|l|l|}
\hline \multicolumn{1}{|c|}{ Smart Grid } & \multicolumn{1}{c|}{ Micro Grid } \\
\hline $\begin{array}{l}\text { Bigger in size and operates at } \\
\text { national level }\end{array}$ & $\begin{array}{l}\text { Smaller andlocal } \\
\text { level / rural areas }\end{array}$ \\
\hline $\begin{array}{l}\text { Load dispatch centre of a large } \\
\text { area }\end{array}$ & $\begin{array}{l}\text { Resources are } \\
\text { monitored by SG }\end{array}$ \\
\hline $\begin{array}{l}\text { Operates broadly, economically } \\
\text { with ICT (Information and }\end{array}$ & $\begin{array}{l}\text { Multiple loads and } \\
\text { many Distributed }\end{array}$ \\
$\begin{array}{l}\text { Communication Technology) to } \\
\text { improve reliability, efficiency, } \\
\text { sustainability of the production. }\end{array}$ & $\begin{array}{l}\text { Energy Resources } \\
\text { (DER)and operates } \\
\text { parallel to Utility } \\
\text { gid. }\end{array}$ \\
\hline
\end{tabular}




\section{B.3 DISTRIBUTED GENERATION (DG):}

Unlike conventional \& centralized large power generating stations, they are de-centralized \& modular generating stations with storage facilities and are close to load centers [12]. The sample schematic diagram of this shown in Fig. 5.

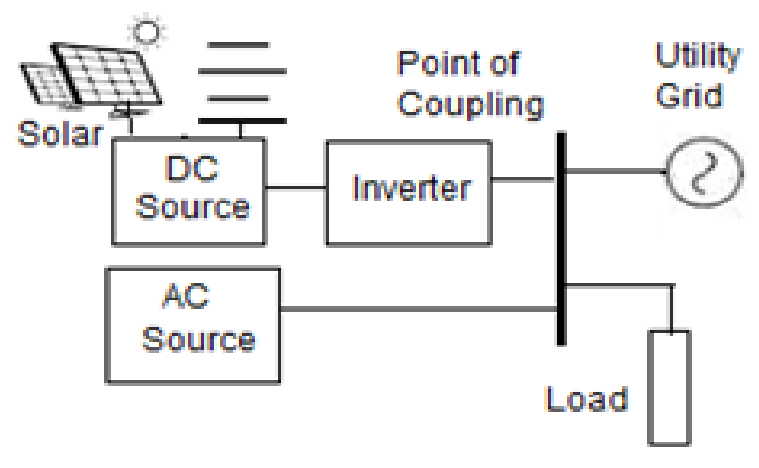

Fig. 5 DG block diagram

They use small Hydro power plants, Micro turbine generators, Solar power plants, Biomass, Biogas, Wind power and Geothermal power units and serves loads up to $10 \mathrm{MW}$ and also being used for power back ups, as shown in Fig. 6.

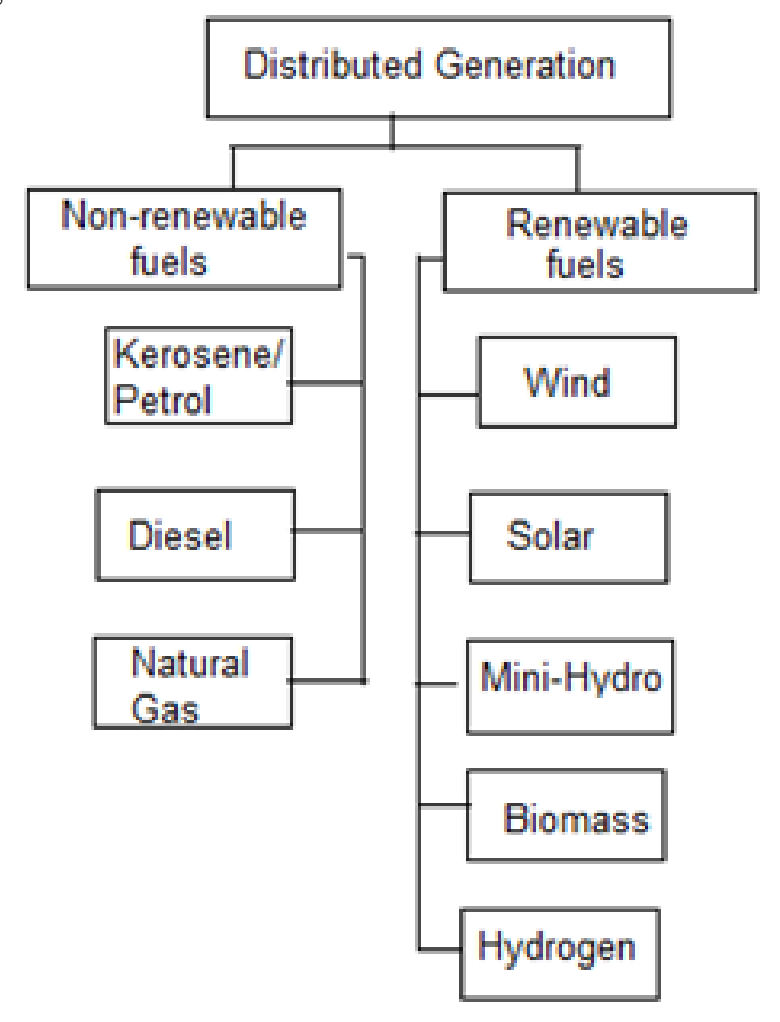

Fig. 6 Various DGs

They can be coordinated with in a SG and have the opportunity to protect environment and improves continuity of supply.

\section{B.4 De-Regulation:}

De-regulation is nothing but phasing out the old vertically integrated utility systems, as shown in Fig. 7, with a restructured model allowing private players in power market as shown in Fig. 8. It is about the redefining the rules, regulations and responsibilities of various players in an Electrical Network [13-14]. It has changed long followed traditional rules and regulations and allowed many players to encourage fair competition. This has allowed better control, increased choices in front of consumers to choose their suppliers, price reductions and optimized resource utilizations etc.

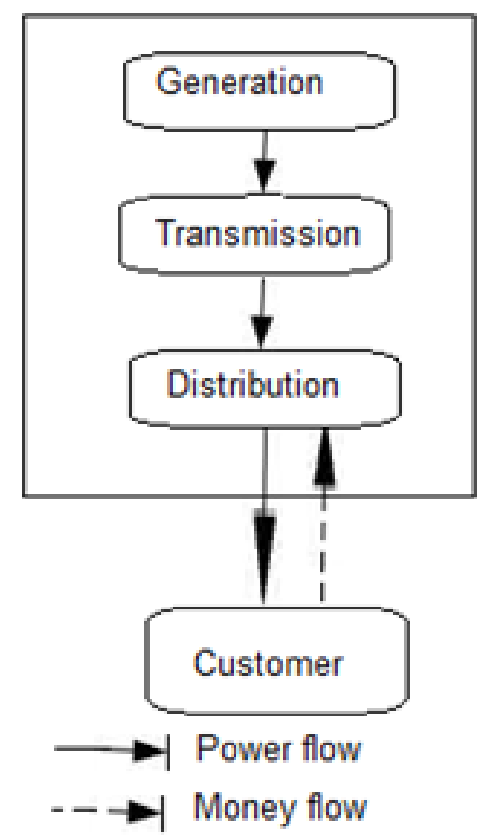

Fig. 7 Vertically integrated utility

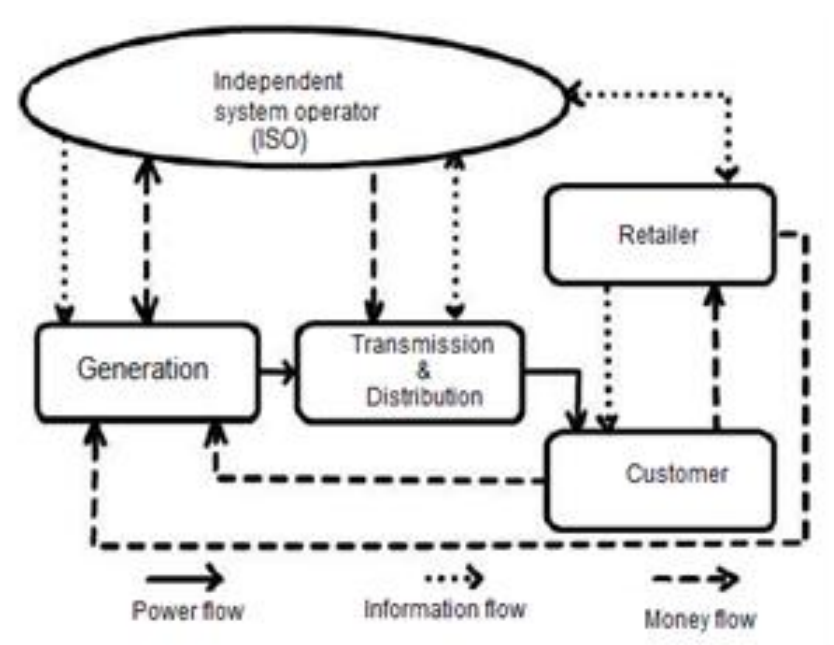

Fig. 8 De-regulated market

But there are so many issues to be observed and taken care in a re-regulated market; one out of them by ISO (Independent System Operator) is shown in Fig. 9. Here the main issues are scheduling and forecasting which are very difficult in practical scenario and are mostly to be resolved with the help of available Intelligent Electronic Devices (IED) and proper communication networking system only. Congestion management is also a big issue which requires continuous feed back from all the elements in restructured market.

Published By:

Blue Eyes Intelligence Engineering 


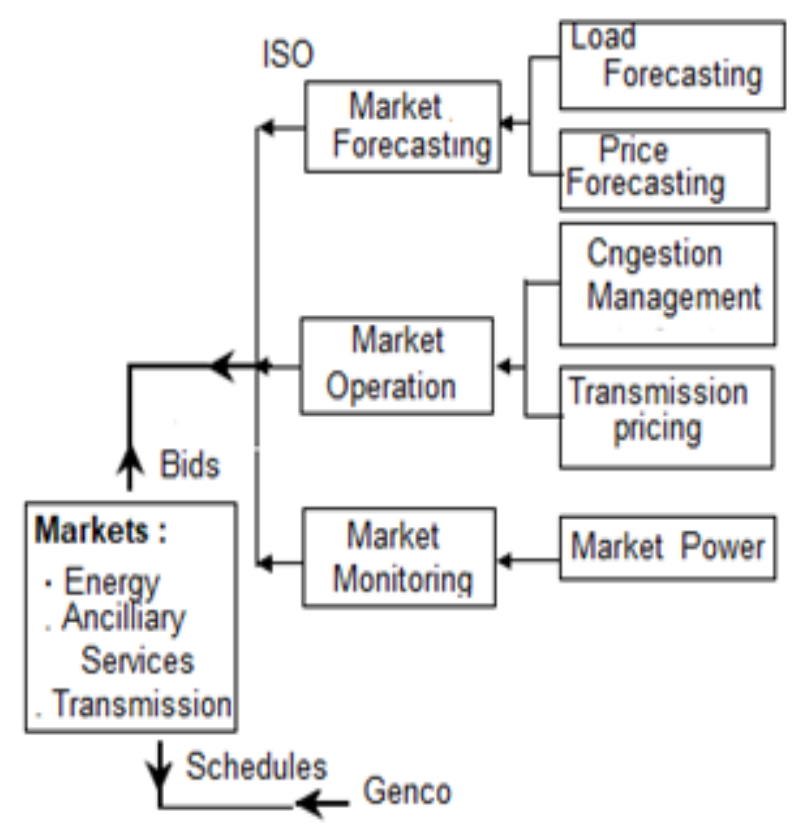

Fig. 9 Restructured market operation

In a nutshell, following are the main entities in de-regulated market :

- Generating Companies (Genco)

- Transmission Companies (Transco)

- Distribution Companies

- Independent System Operator (ISO)

- Retail Energy Service Providers

- Customers

- Regulators

\section{B.5 Internet Of Things (IOT):}

IOT is an ecosystem of connected physical objects that are accessible through the internet with the use of electronic controllers and sensors. It is started as activity to provide identification and connecting all the relevant elements in a process system the data shared here will be used by all the connected elements in it. IOT makes the interconnection between various sensor devices \& platforms and can do more fruitful jobs in smart cities, energy management, health care and smart grids among others. It comprises of millions \& billions of smart devices to the cloud and acts as a data collector. It is promoting the real time monitoring and analysis of electric power system parameters of various deices spread all the corners of globe. With the evolution of Artificial Intelligence (AI), it is possible to transform IOT connected devices into decision-making assistants for man-kind's modern day of living. It is allowing Device-to -Device (D2D) and Machine-to-Machine (M2M) communication and data sharing for their efficient working. It is being widely used in safety systems (like gas leak and smoke detection) and intrusion detection for security system strengthening. The schematic diagram of an IOT facility is shown in Fig. 10[15]. Raw data like current, voltage, temperature from sensors are given to the Programmable Logic Controllers (PLC) from where any system can be easily controlled.

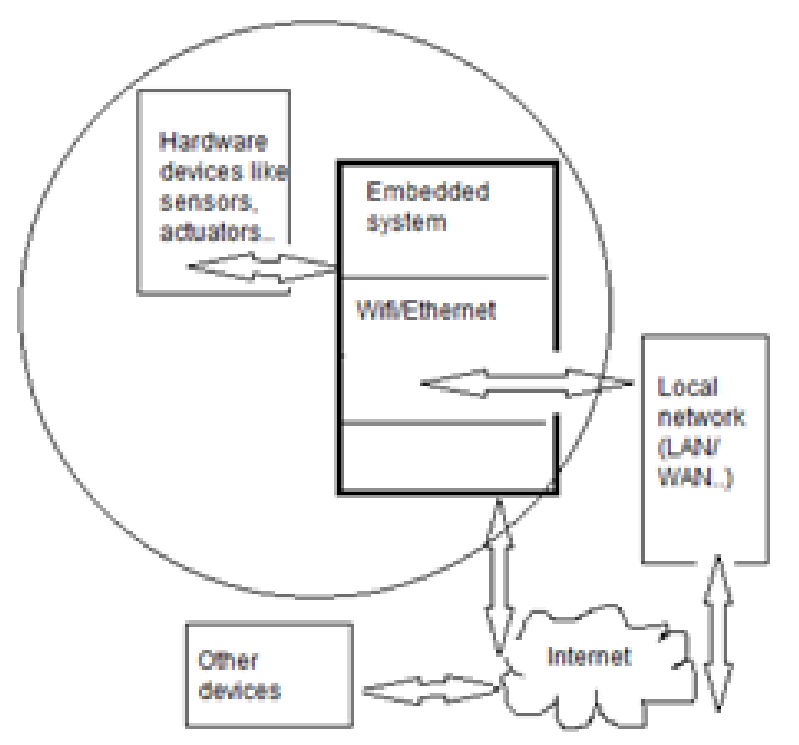

(a) Concept of IOT

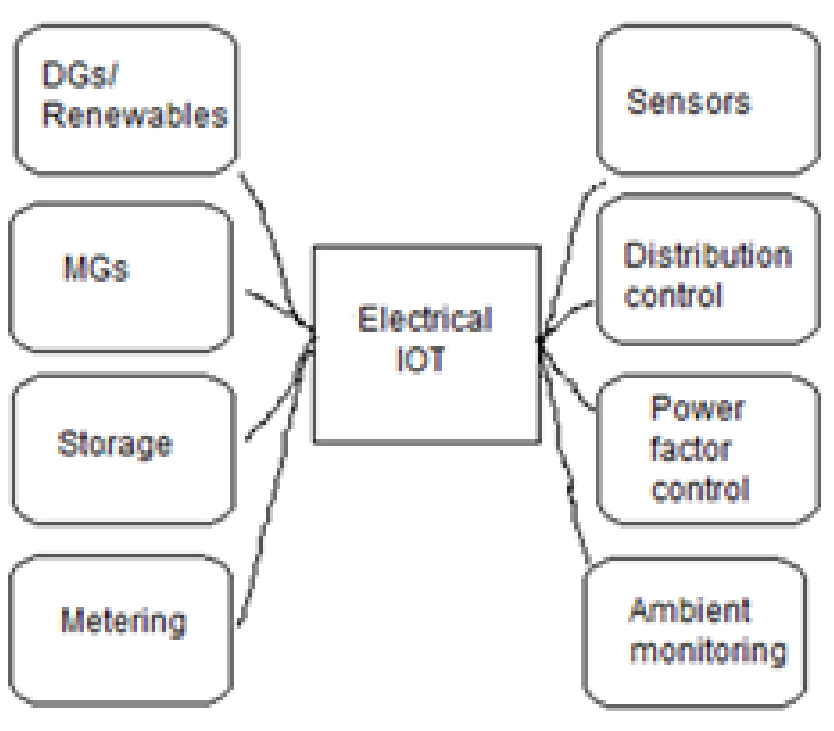

(b) IOT for Electrical power system

Fig. 10 IOT model

\section{B.6 GRID OF THINGS (GOT):}

The electric grid is intelligently controlled remotely in an efficient and effective manner by connecting all the components of transmission, substation and distribution and termed as GOT [16]. With the wide spread of IOT, power grids are being treated as Grid of Things (GOT) so as to work as fully automated grid with improved grid security, improved voltage \& frequency profile and stability. Supervisory Control and Data Acquisition (SCADA) system is one such example which is a control system architecture that uses computers, networked data communications and graphical user interfaces for supervisory management wherein PLCs interface with the process plant or machinery. A schematic is shown in Fig 11. 


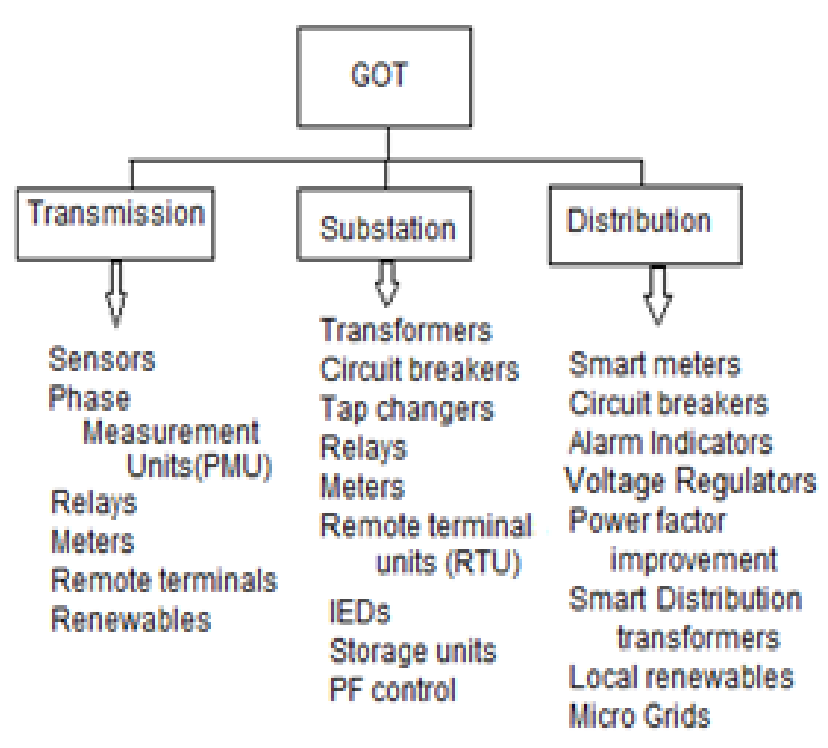

Fig. 11 GOT Model

\section{B.7 HOLISTICALLY ORCHESTRATED THINGS (HOT):}

It is an integrated entity of IOT and GOT [16-18] as shown in Fig 12, to control smart assets, sensitive communication networks to give accurate returns to a business entity. The holistic orchestration of millions of devices in a power system network is leading to an energy-efficient operation of all the systems. Orchestration is enabling to integrate with other systems like cloud computing, enterprise IT, and mobility applications. It is improving the processes capability and synchronizing data smoothly.

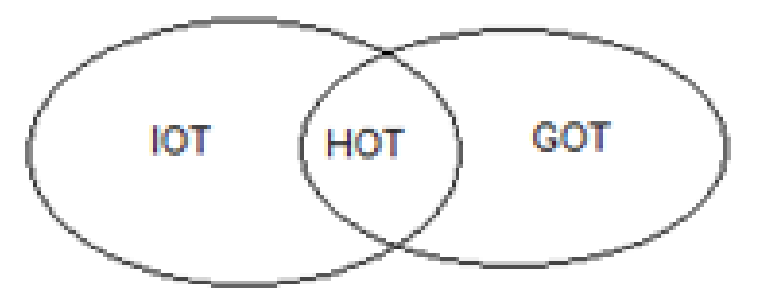

Fig. 12 Concept of HOT

\section{B.8 RETROFITS/RENOVATIONS:}

When any system is with all-new equipment, their availability is high with reduced break downs along with low maintenance costs. Whereas the ageing process deteriorates the equipment due to wear \& tear, voltage \& load stresses, harmonics etc. Here two options are available; one is Run-to-failure and the other one replace them timely. For the age old equipment and technically obsolete components, the best option is to retrofit them with new equipment by utilizing the existing space and other hardware [19]. This type of renovations will reduce the breakdowns and operating \& maintenance costs. These retrofits can be done at user area and can extend the life of equipment for many more years with latest components and technology.

\section{IV.COMMUNICATION\& RESULTS}

With the increased reliance on electrical power, there are the needs to improve the reliability of system. Communication system plays an important role in electrical power system which is transforming into smart mode with an
End-to-End (E2E) data sharing continuously rather always at real times in two-way mode unlike traditional one-way mode. Communication networks are being used to provide control the power flow with various switching devices like circuit breakers and other components which improves reliability. In today's two-way communication networks with the support from IT encapsulated by Computers and IEDs, all the components are communicating themselves and with others. The so called Modern electrical power systems are mostly man-made systems comprising of demand forecast, generation planning \& scheduling, renovated transmission and distributed system with a suitable communication system as shown in Fig 13.

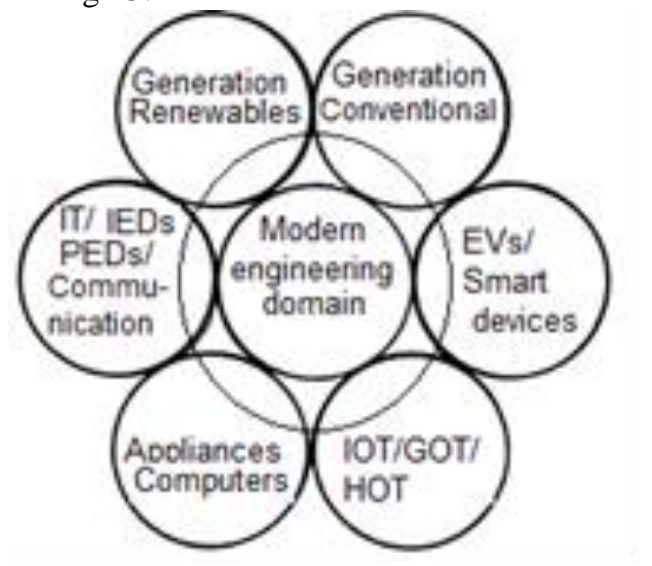

Fig. 13 Modern engineering model

Nowadays power system communication plays a vital role for a safe, real time and efficient operation and control in modern power systems. This will enable to effectively transfer data between various elements of power communication networks for smooth operation of the entire system. The examples being fiber optics, Power Line Carriers, Radio system wireless with low orbit satellites, Microwaves, Packet Switched Network(PSN) [20], LAN, NAN, WAN etc. The schematic an example of how NAN, HAN and WAN are used is shown in Fig. 14. Due to higher costs of the above schemes, SCADA is being widely used in many distributed networks.

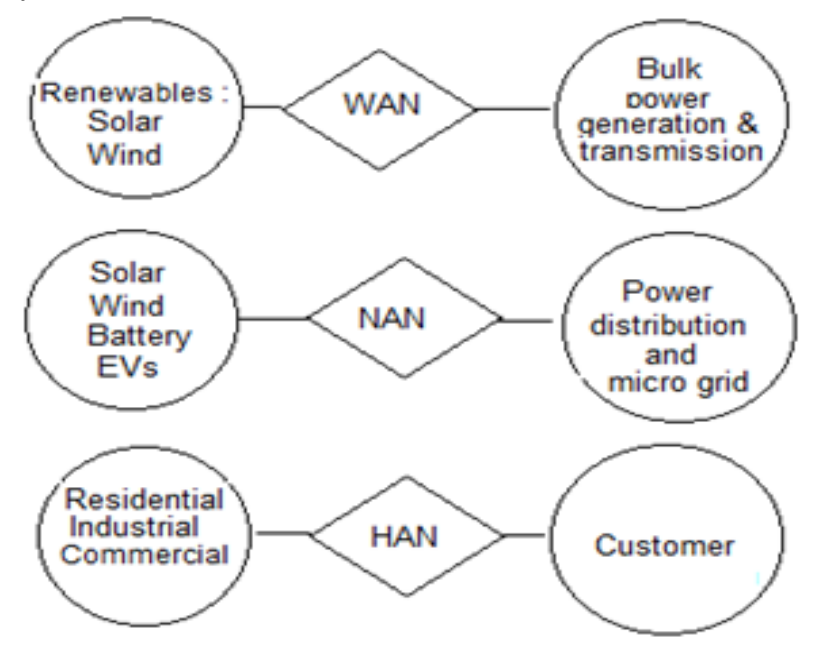

Fig. 14 Application WAN, NAN and HAN

Published By:

Blue Eyes Intelligence Engineering

\& Sciences Publication 


\section{CONCLUSION}

Sustainability - Dependability - Reliability - Availability Maintainability (SDRAM) has become very important in present era of electrical power system. The tedious and challenging job of electrical engineer in the modern era has become somewhat easy with more dependability on the use of IT and Computers in Electrical engineering field. Modern power system can be made more effective almost to the degree of $100 \%$ availbility, reliable to the levels of $98 \%$ due to increased fault avoidance, and almost $100 \%$ efficient with the help of various software and communication techniques. The envisaged threats can be taken as opportunities and make the electrical power system more stable to ensure high quality by using latest PEDs \& IEDs. Also the available electrical simulation software programs like ETAP (Electrical Transient Analyzer Program), MATLAB (software for numerical computing), PSPICE (Electrical schematic software), Power Tools (electrical simulations), LABVIEW (designing, interfacing and HMIs) etc. are helping largely to analyze and maintain the modern electrical networks easily. The role of computers and their interface in design, analysis and operation of both electrical and electronic systems is revolutionary in electrical engineering and most of the jobs are getting done more accurately with an error rate of 9X10-10. Also the various available communication technologies are making the complex control monitoring systems easy and helping the society as a whole to make the electricity as a powerful tool for a sustainable development.

\section{REFERENCES}

1. NarainG.Hingorani, Laszlo Gyugyi, "Understanding FACTS”, IEEE Press, 2000.

2. K.R.Padiyar, "HVDC transmission systems", 2nd edition New Age International Publications-2005.

3. RaghvendraprasadDeshpande, M. S. Raviprakasha, "Power system communications: Recent trends, technologies and future - A comprehensive literature scan", IEEE, International Conference on Energy Systems and Applications, Nov 2015.

4. S. Chen, B. Mulgrew, and P. M. Grant, "A clustering technique for digital communications channel equalization using radial basis function networks," IEEE Trans. on Neural Networks, vol. 4, pp. 570-578, July 1993.

5. https://www.worldenergy.org/news-and-media/news/glo bal-energy-consumption-to-2040/S, accessed on 13 July, 2019.

6. B. Koti Reddy, "Safety in use of electrical appliances", International Journal for Research \& Development, Volume 7, Issue 46-June-2019. Volume 7, Issue 46, June-2019.

7. B. Ramakoti, S.et.al, B.Koti Reddy, "Study of Fault Currents and Relay Coordination of a Chemical Industry After Integrating with PV Generation and Simulation with a Software", International Journal of Engineering Trends and Technology, Volume 42, Number 5, Dec-2016.

8. Janaka B. Ekanayake, Nick Jenkins,...,Akihiko Yokoyama, “ Smart Grid: Technology and Applications", John Wiley \&Sons, 2012.

9. NouredineHadjsaid, Jean-Claude Sabonnadiere, "Smart Grids", ISTE(UK) and John Wiley \&Sons(USA), 2012.

10. Zubair Md. Fadlullah, Nei Kato, "Evolution of Smart Grids", Springer International Publishing House-2015.

11. Jianzhong Wu, Y.et.al, "Comparison of the development of Smart Grids in China and the United Kingdom", IEEE
PES Innovative Smart Grid Technologies Conference Europe (ISGT Europe)-2010.

12. KRS Kashyap, B.Dheeraj Reddy, "Ancillary services and stability analysis of distributed generation systems", International Journal of Engineering research and applications, volume 3, Issue 3-May-June-2013.

13. Online course at https://nptel.ac.in/syllabus/108101005 on Restructured Power systems (Web), NPTEL.

14. Steven Stoft, "Power System Economics: Designing Markets for Electricity", Wiley-IEEE Press-2002.

15. https://en.wikipedia.org/wiki/Internet_of_things, accessed on 10 July 2019.

16. https:/electricenergyonline.com/energy/magazine/1036/ar ticle/What-is-between-Grid-of-Things-GoT-and-Internetof-Things-IoT-is-HoT-Holistically-Orchestrated-Thingshtm, accessed on 12 July 2019.

17. DimitriosSikeridis, EiriniEleni,Tsiropoulou, Michael Devetsikiotis, SymeonPapavassiliou, "Energy efficient orchestration in wireless powered internet of things infrastructure", IEEE Transactions on Green Communications and Networking, Volume: 3 , Issue: 2 , June 2019.

18. Anthony, Rik irons-mclean, Mmarceloyannuzzi, "Orchestrating and automating security for the internet of things", Cisco Press-2018.

19. B. Koti Reddy, "Retrofit of MOCB with VCB", International Journal of Research in Engineering, Science and Management, Volume 2, Issue 6-June-2019.

20. Dr. M.Khedkar, Dr. G.M.Bhole, "A text book of electric power distribution automation”, University Science Press, Laxmi publications-2010. 